\title{
A qualitative exploration of the enablers and barriers to the provision of outpatient clinics by hospital pharmacists.
}

Gerald Bailey ( $\sim$ gerald.bailey1991@gmail.com )

Brownlee Centre for Infectious and Communicable Diseases: Gartnavel General Hospital https://orcid.org/0000-0002-9599-1358

Emma Dunlop

Strathclyde Institute of Pharmacy and Biomedical Sciences

Paul Forsyth

NHS Greater Glasgow and Clyde Primary Care Division: NHS Greater Glasgow and Clyde https://orcid.org/0000-0003-3804-6795

\section{Research Article}

Keywords:

Posted Date: March 3rd, 2022

DOI: https://doi.org/10.21203/rs.3.rs-1187718/v1

License: @ (i) This work is licensed under a Creative Commons Attribution 4.0 International License. Read Full License 


\section{Abstract}

Background: With increasing demands on the National Health Service (NHS), Scottish Government-led pharmacy strategy has prioritised the development and expansion of modern outpatient services. Pharmacist-led outpatient clinics have been shown to reduce hospital admissions and improve patient outcomes. However, expanding these contemporary models of care has proved challenging, and there are few qualitative data about the factors affecting the provision of these.

Aim: This study aimed to explore the enablers and barriers to hospital pharmacists providing outpatient clinics within the largest health authority in Scotland, NHS Greater Glasgow \& Clyde (NHSGGC).

Method: Between August and October 2020, one-to-one semi-structured interviews were conducted virtually using the videoconferencing platform Microsoft Teams $^{\circledR}$, with NHSGGC hospital pharmacists. Audio- and video-recordings of the interviews were transcribed in verbatim and underwent thematic analysis.

Results: 16 hospital pharmacists were interviewed; $50 \%$ were clinic providers and $50 \%$ were not. Analysis generated seven themes: clinical or service need, individual psychological factors, clinic structure and processes, additional clinical skills and training, competing priorities, macro-level pharmacy working, and external stakeholder relationships.

Conclusion: The enablers and barriers to hospital pharmacists providing outpatient clinics are multifaceted. Changes are required at the micro- and macrolevel, with distributed leadership and system transformation remaining crucial. The forthcoming implementation of new professional curricula, should reconfirm whose role it is to develop such services and may enable pharmacists to overcome the individual and systematic barriers that prevent them from currently progressing the development of modern outpatient services; prospective research needs to accompany this vision.

\section{Impact Of Findings On Practice}

- The barriers and enablers to the provision of a pharmacist-led outpatient clinic described in this study provide a basis for better understanding the qualitative themes contributing to the discord between individual and systematic leadership and service transformation responsibilities.

- The implementation of new professional curricula may offer potential solutions to distributed leadership models and ultimately outpatient service provision

- Future research should evaluate the impact of such an approach and implementation science frameworks may also offer additional means to realise this change at the macro-level.

\section{Introduction}

Day-to-day roles of pharmacists worldwide have developed over the last thirty years beyond traditional dispensing roles, to now also include tasks relating to medication: review, optimisation, and monitoring [1]; such roles are known to improve patient outcomes and treatment goals [2, 3]. Additionally, in many countries pharmacists have been provided with the legal premise to prescribe medicines; and there is growing evidence that the benefits of autonomous non-medical prescribers, including pharmacists, are comparable to those delivered by medical prescribers in many countries and settings [4,5]. There has also been a global movement towards increased professional recognition and credibility for advanced pharmacy practice and specialist pharmacists [6, 7]. However, there remains a need for clarity around the definition, scope and extent of these advanced practices and specialisms; with international variations in these advanced pharmacy frameworks and workforce delivery models [6-9].

United Kingdom (UK) legislation has enabled pharmacists to become independent prescribers upon successful completion of an accredited course; this usually consists of university-based taught components and experiential based learning [10, 11]. Pharmacist Independent Prescribers (PIPs) have demonstrated their benefits for inpatients whilst working in the acute hospital-based setting [12, 13]. However through clinic provision, PIPs have also shown their value for outpatients by optimising medicines with known prognostic importance [14, 15]. In Scotland, changes in public health pose sustainability challenges to the National Health Service (NHS), requiring a modernisation of the multidisciplinary skill mix and sector of care in which care is delivered [16-21].

Scottish Government pharmacy strategy has prioritised utilising the expertise of pharmacists to improve the delivery of services, such as outpatient services and clinics [22]. For hospital pharmacists, a major component of these services is the provision of a modern outpatient programme which encompasses the greater use of PIPs in specialist clinics within both community- and hospital-based settings. [22, 23]. Exemplar models of pharmacist-led clinics utilising advanced skills and independent prescribing (IP) qualification, in specialties like cardiology, have produced measurable benefits [24]. However, the expansion of these clinic models into other specialities is limited.

There appears to be few worldwide qualitative data about the enablers and barriers to the provision of pharmacist-led clinics which is perhaps indicative of how this specialist outpatient role is still in its relative infancy. Findings from a tri-continental study which includes pharmacists, are limited by their aggregation with that of other healthcare professionals (HCPs), meaning pharmacist-specific enablers and barriers are non-extractable [25]. Other exploratory studies only address the behavioural intentions and expectations of hospital pharmacists potentially expanding their services, with no practical/real-life observations and information about service expansions and provision [26, 27].

\section{Aim}


This study aimed to explore the enablers and barriers to hospital pharmacists providing outpatient clinics within the largest health authority in NHS Scotland. The rationale for the study was to provide findings that would help inform future national implementation strategies.

\section{Ethics approval}

The NHS West of Scotland Research Ethics Service Scientific Officer advised that ethical review was not required, on the basis that this study was a service evaluation aiming to deliver government strategy [22]. Approval was obtained, from local governance teams within the health authority, as this study formed part of a wider pharmacy service evaluation.

\section{Method}

\section{Setting}

This study was conducted within NHS Greater Glasgow \& Clyde (NHSGGC), the largest autonomous regional health authority in Scotland which provides healthcare to a population of 1.14 million residents [28]. 34\% of the most socially and economically deprived areas in Scotland are within the NHSGGC authority [29].

\section{Sampling}

Our purposive sampling strategy aimed to recruit pharmacists working within different hospital sites and specialties (e.g. cardiology, oncology, mental health), as well as different levels of hospital and clinic experience [30,31]. A sample of between 12-20 participants was estimated to potentially achieve data saturation [31-34], whilst we intended to have an equal number of hospital pharmacists who provided, and did not provide, an outpatient clinic The intended goal of the sample was to provide a breadth of experiences about both the enablers and barriers to outpatient clinic provision.

Participant inclusion criteria were permanent or fixed-term employed hospital pharmacists of any level, pay grade, or seniority; who worked in any of the ten acute hospital sites within NHSGGC [28]. Exclusion criteria included: those on maternity/paternity or sick leave at the time of the study; and the researchers, who were pharmacists, involved in the study. Additionally, pharmacists with less than 2 years post-registration experience were excluded since they would've been in an early career training position and would be ineligible to gain the additional qualifications (e.g. IP) and experience that are needed to potentially provide a pharmacist-led outpatient clinic [10,11].

\section{Participant recruitment}

A participant information leaflet was disseminated in an internal email in February 2020 by the lead pharmacist for all hospital pharmacists within NHSGGC; a reminder email was sent two weeks later. All interested participants were invited to contact the lead author by email or telephone, who issued consent forms that were completed and returned by email or post. No incentives were offered for participation.

\section{Data collection and handling}

Prior to the interviews, two semi-structured interview schedules (one for those who provided pharmacist-led clinics and one for those who did not; see Supplementary File) were piloted on one independent pharmacist with 4 months experience of outpatient service provision, then modified and developed for use; this pilot interview data were excluded from the study. Due to the COVID-19 pandemic, interview dates were postponed and took place between August and October 2020. At this point each participant was contacted and invited to participate in an online interview using the videoconferencing platform Microsoft Teams ${ }^{\circledR}[35]$. At the interview, each participant reaffirmed their consent verbally and were informed that the main purpose of the interview was to explore their own views and experiences on clinic provision, and to describe factors that enabled or prevented them from doing this. All interviews lasted between 15-30 minutes, and were video-recorded; these interviews were subsequently transcribed in verbatim and anonymised (GB). These transcripts were then accuracy checked by an independent staff member who did not take part in the study. All electronic data were stored on encrypted and password protected NHS computers. After transcription and validation, all recordings were deleted.

\section{Data analysis}

Both coders (GB and PF) were male pharmacists, with a range of experience from 6 to 19 years working in hospital and community-based pharmacy respectively. All transcripts were uploaded onto the qualitative data analysis software NVivo 12.0 (QSR International Pty Ltd.) [36]. All transcribed data underwent thematic analysis using Braun and Clarke's recommended six phases [37, 38]. After familiarisation with the raw transcript data, and with a primary focus on the study aim, an inductive approach was used to segment the data into meaningful categories and descriptors (i.e. generating initial codes). One quarter $(n=4)$ of all transcriptions were independently coded (GB and PF), with a random number generator used to select transcripts. From this, a preliminary coding scheme was produced, and applied, across all past and future interviews; transcripts were reviewed continuously with constant comparisons made between the generated codes and the data to allow the incorporation of consistent and differing responses (GB). Patterns of this coded data were collated into broader concepts which linked them together (i.e. themes) [37-39]. The derivation, review, and refinement of themes were discussed regularly (GB and PF), and continued until each theme was defined and had a clear narrative that was relevant to the aim of this study. Analysis continued concurrently with further participant recruitment until data saturation was achieved; further participant recruitment stopped at this stage [37, 42]. Once all interviews were included, and to provide an external check on the data and analysis process, these themes and sub-themes were debriefed and validated by an experienced qualitative research associate (ED) [38, 40,41]. Differences in interpretation were resolved by consensus; both semantic and latent themes, with sub-themes, emerged from the data. The reporting of this study conforms to the consolidated criteria for reporting qualitative studies (COREQ) guidelines (see Supplementary File) [43]. 


\section{Results}

Data saturation was achieved after 16 hospital pharmacists were interviewed; their characteristics are presented in Table 1. Most participants were female $(n=11)$ and median age was 38 years. Other professional and demographic characteristics were broadly similar between the clinic- and non-clinic-providing pharmacist cohorts. Analysis generated seven themes relating to enablers and barriers; many of these were interdependent and had the potential to be an enabler or a barrier to clinic provision, depending on the context or individual. A narrative of each theme and sub-theme is detailed below and illustrative quotes for each are presented in Table 2. 
Table 1

Characteristics of participating pharmacists

\begin{tabular}{|c|c|c|c|}
\hline Variables & $\begin{array}{l}\text { Pharmacists who provided } \\
\text { a clinic } \\
(n=8)\end{array}$ & $\begin{array}{l}\text { Pharmacists who did not } \\
\text { provide a clinic } \\
(n=8)\end{array}$ & $\begin{array}{l}\text { Both cohorts } \\
\text { combined } \\
(n=16)\end{array}$ \\
\hline Participants & $\begin{array}{l}\text { P1, P2, P4, P5, P6, P8, P10, } \\
\text { P13 }\end{array}$ & $\begin{array}{l}\text { P3, P7, P9, P11, P12, P14, P15, } \\
\text { P16 }\end{array}$ & \\
\hline Age, years & $38.5(31.0-42.5)$ & $35.0(29.5-39.5)$ & $38.0(30.5-40.0)$ \\
\hline \multicolumn{4}{|l|}{ Median (IQR) } \\
\hline Gender, $\mathrm{n}$ & 5 & 6 & 11 \\
\hline Female & 3 & 2 & 5 \\
\hline \multicolumn{4}{|l|}{ Male } \\
\hline $\begin{array}{l}\text { Time qualified as a pharmacist, } \\
\text { years Median (IQR) }\end{array}$ & $16.0(8.0-20.5)$ & $12.0(6.5-16.5)$ & $15.5(7.5-18.0)$ \\
\hline $\begin{array}{l}\text { Time practising as a hospital } \\
\text { pharmacist, years Median (IQR) }\end{array}$ & $13.0(8.0-19.5)$ & $12.0(6.5-16.0)$ & $12.5(7.5-16.5)$ \\
\hline Achieved an Independent & 8 & 7 & 15 \\
\hline \multicolumn{4}{|l|}{ Prescribing qualification, $\mathrm{n}$} \\
\hline Time qualified as an Independent & $3.8(2.0-8.3)$ & $2.1(0.3-3.0)$ & $3.0(0.8-4.5)$ \\
\hline \multicolumn{4}{|l|}{ Prescriber, years Median (IQR) } \\
\hline NHS Pay Grade/ Banding, ${ }^{a} \mathrm{n}$ & 0 & 1 & 1 \\
\hline Band 6 & 2 & 3 & 5 \\
\hline Band 7 & 5 & 3 & 8 \\
\hline Band $8 a$ & 1 & 1 & 2 \\
\hline \multicolumn{4}{|l|}{ Band 8b } \\
\hline Working time per week, ${ }^{b}$ hours & $37.5(32.8-37.5)$ & $35.75(30.0-37.5)$ & $37.5(30.0-37.5)$ \\
\hline \multicolumn{4}{|l|}{ Median (IQR) } \\
\hline Frequency of rotation through more than one specialty in their & 7 & 4 & 11 \\
\hline current role, $n$ & 0 & 3 & 3 \\
\hline Doesn't occur in current role & 1 & 0 & 1 \\
\hline Daily & 0 & 1 & 1 \\
\hline \multicolumn{4}{|l|}{ Weekly } \\
\hline \multicolumn{4}{|l|}{ Monthly } \\
\hline Additional post-graduate & 4 & 5 & 9 \\
\hline qualifications, $n$ & 4 & 5 & 9 \\
\hline \multicolumn{4}{|l|}{ Post-graduate diploma } \\
\hline \multicolumn{4}{|l|}{ Masters degree } \\
\hline Additional clinical skills/training, ${ }^{\mathrm{d}} \mathrm{n}$ & 5 & 6 & 11 \\
\hline Clinical skills & 2 & 3 & 5 \\
\hline Consultation skills & 1 & 0 & 1 \\
\hline Advanced clinical assessment & 1 & 0 & 1 \\
\hline Venepuncture & & & \\
\hline
\end{tabular}




\begin{tabular}{|c|c|c|c|}
\hline Variables & $\begin{array}{l}\text { Pharmacists who provided } \\
\text { a clinic } \\
(n=8)\end{array}$ & $\begin{array}{l}\text { Pharmacists who did not } \\
\text { provide a clinic } \\
(n=8)\end{array}$ & $\begin{array}{l}\text { Both cohorts } \\
\text { combined } \\
(n=16)\end{array}$ \\
\hline \multicolumn{4}{|c|}{ 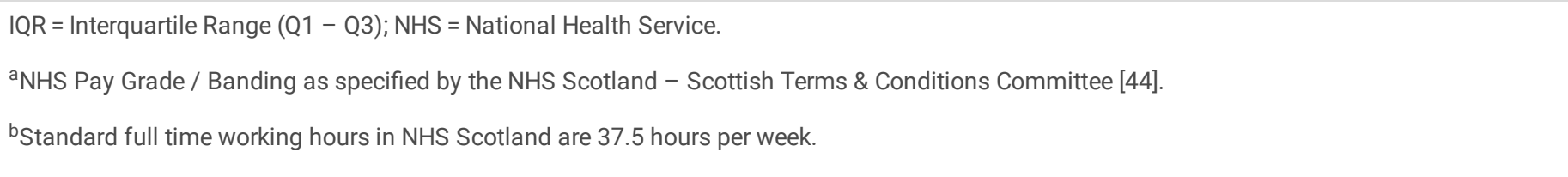 } \\
\hline
\end{tabular}


Table 2

Illustrative quotes from interviews highlighting themes and sub-themes

\begin{tabular}{|c|c|c|c|}
\hline Theme & Sub-Theme & Exemplar Enabler Quote & Exemplar Barrier Quote \\
\hline $\begin{array}{l}\text { Clinical or } \\
\text { service need }\end{array}$ & $\mathrm{N} / \mathrm{A}$ & $\begin{array}{l}\text { '... [the clinic] really worked and happened quickly for me because } \\
\text { the directorate needed it to happen.' (P5) }\end{array}$ & $\mathrm{N} / \mathrm{A}$ \\
\hline \multirow[t]{6}{*}{$\begin{array}{l}\text { Individual } \\
\text { psychological } \\
\text { factors }\end{array}$} & $\begin{array}{l}\text { Personal } \\
\text { motivation }\end{array}$ & $\begin{array}{l}\text { 'I think it [providing a clinic] would give people a huge sense of } \\
\text { job satisfaction as well... it is something I am definitely keen to } \\
\text { do in the near future.' (P11) }\end{array}$ & $\mathrm{N} / \mathrm{A}$ \\
\hline & \multirow[t]{2}{*}{ Confidence } & \multirow{2}{*}{$\begin{array}{l}\text { 'I had a lot of experience of working with inpatient cardiology; so, } \\
\text { I had a pretty good understanding of the background for } \\
\text { medicines and treatment rationale...it's like anything, once you do } \\
\text { it [the clinic] long enough that level of anxiety or trepidation } \\
\text { decreases as you become more confident and familiar with the } \\
\text { processes.' (P10) }\end{array}$} & $\begin{array}{l}\text { Lack of confidence in clinical decision making: } \\
\text { '...but you won't have that security because } \\
\text { you'll have to make the decisions all by } \\
\text { yourself.' (P12) }\end{array}$ \\
\hline & & & $\begin{array}{l}\text { Fear of the potential clinical risks: 'I am still } \\
\text { actually quite terrified of being alone with a } \\
\text { patient, within a room.' (P4) }\end{array}$ \\
\hline & \multirow[t]{3}{*}{$\begin{array}{l}\text { Locus of } \\
\text { Control }\end{array}$} & \multirow{2}{*}{$\begin{array}{l}\text { Internal Locus of Control: 'I feel you really have to push the doors } \\
\text { open yourself because things aren't going to come for you. } \\
\text { You've got to show the value of a pharmacy service because } \\
\text { nobody is going to come up to you and say, "Here's a big pool of } \\
\text { money, can you set up a clinic?".' (P5) }\end{array}$} & $\begin{array}{l}\text { External Locus of Control: 'How can that be } \\
\text { done without getting permission...?' (P15) }\end{array}$ \\
\hline & & & \multirow{2}{*}{$\begin{array}{l}\text { Needs solutions \& resource provided directly: } \\
\text { 'So we did approach our senior pharmacy team } \\
\text { and asked if we could do this and we were told } \\
\text { that we didn't have the money to pay for it.' } \\
\text { (P16) }\end{array}$} \\
\hline & & $\begin{array}{l}\text { Leadership leading to creative solutions: '... we had put a model } \\
\text { together for a clinic and with the MCN, everybody had agreed that } \\
\text { there was a need for pharmacist input and we went out and got } \\
\text { our own money for it... we put in a grant application [to a drug } \\
\text { company] and there was money given for technicians, as well as } \\
\text { pharmacist's time.' (P14) }\end{array}$ & \\
\hline \multirow[t]{5}{*}{$\begin{array}{l}\text { Clinic } \\
\text { structure and } \\
\text { processes }\end{array}$} & $\begin{array}{l}\text { Defined } \\
\text { Patient } \\
\text { Cohorts }\end{array}$ & $\begin{array}{l}\text { 'When I first started, I only saw rheumatoid arthritis patients but I } \\
\text { now see all different types of patients.' (P6) }\end{array}$ & $\mathrm{N} / \mathrm{A}$ \\
\hline & $\begin{array}{l}\text { Integration } \\
\text { within } \\
\text { standard } \\
\text { patient } \\
\text { treatment } \\
\text { pathways }\end{array}$ & $\begin{array}{l}\text { 'she [consultant] really had a vision for where the pharmacist } \\
\text { would fit into her clinic, and it was quite a pre-defined role that } \\
\text { was easier to train towards because she knew what the goal was } \\
\text { for the pharmacist...' (P2) }\end{array}$ & $\mathrm{N} / \mathrm{A}$ \\
\hline & $\begin{array}{l}\text { Exemplar } \\
\text { Peers }\end{array}$ & $\begin{array}{l}\text { Exemplar Peer Present: '...he [external pharmacist peer] was trying } \\
\text { to establish the service, along with one of the consultants. So, I } \\
\text { was lucky in a sense that there was an established service within } \\
\text { the [hospital] which I could tap into.' (P10) }\end{array}$ & $\begin{array}{l}\text { Exemplar Peer Absent: '...but it's just not } \\
\text { something so far that has historical } \\
\text { precedence. So, that in itself is a barrier. Just } \\
\text { that these things don't exist yet.' (P3) }\end{array}$ \\
\hline & \multirow[t]{2}{*}{$\begin{array}{l}\text { Practical and } \\
\text { administrative } \\
\text { Support }\end{array}$} & \multirow[t]{2}{*}{$\begin{array}{l}\text { Increasing knowledge of, and gaining administrative support for, } \\
\text { the practical elements: 'It was mostly just the technical side of } \\
\text { things I needed help with like, "Will I get a space? How do } \\
\text { patients get appointed to my clinic? Will someone be able to do } \\
\text { my dictations?" ... I spoke to the administration manager and she } \\
\text { arranged for an assigned audio typist who now does all my } \\
\text { dictations...just someone showing you how to work a Dictaphone } \\
\text { and how to approve your clinic letters is important.' (P5) }\end{array}$} & $\begin{array}{l}\text { Lack of knowledge of the clinic processes } \\
\text { hindering its establishment: 'I guess, I was } \\
\text { maybe a bit too enthusiastic and naïve in the } \\
\text { beginning by thinking, "this is such a fantastic } \\
\text { opportunity, and I can't wait to get stuck in" ... } \\
\text { but I don't think you could start a clinic without } \\
\text { considering all these [practical] aspects...' (P16). }\end{array}$ \\
\hline & & & $\begin{array}{l}\text { Need for administrative support: '...I know it is } \\
\text { very time consuming to do dictations or to do } \\
\text { your own letters. So, we need to ensure we do } \\
\text { have admin support for that, and I think that } \\
\text { these are things that even the doctors struggle } \\
\text { with at the moment within our service.' (P16) }\end{array}$ \\
\hline \multirow[t]{3}{*}{$\begin{array}{l}\text { Additional } \\
\text { clinical skills } \\
\text { \& training }\end{array}$} & \multirow[t]{2}{*}{$\begin{array}{l}\text { Prescribing, } \\
\text { examination, } \\
\text { and } \\
\text { consultation } \\
\text { skills }\end{array}$} & \multirow{2}{*}{$\begin{array}{l}\text { '...during my prescribing course, I've picked up all the skills for } \\
\text { clinical assessment and consultation through those [NHS } \\
\text { Education for Scotland] study days and then I went on to do an } \\
\text { advanced clinical skills assessment course after I qualified... over } \\
\text { time, definitely with practice and experience, picking up more, } \\
\text { seeing more patients, that has all helped me to provide the } \\
\text { service more confidently.' (P8) }\end{array}$} & $\begin{array}{l}\text { Need for independent prescribing: 'I wasn't a } \\
\text { prescriber when I first started doing this clinic... } \\
\text { and it meant I was having to get medics or } \\
\text { other pharmacists to write all my prescriptions } \\
\text { for me after seeing patients in clinic.' (P1) }\end{array}$ \\
\hline & & & $\begin{array}{l}\text { Need for leaming \& updating clinical skills: 'So } \\
\text { that [examining patients] would be completely } \\
\text { new to me, and doing face to face } \\
\text { consultations. So, I would need to go on } \\
\text { courses for that, and even expand on my IP.' } \\
\text { (P7) }\end{array}$ \\
\hline & $\begin{array}{l}\text { Mentorship } \\
\text { and } \\
\text { preceptorship } \\
\text { of clinical } \\
\text { skills }\end{array}$ & $\begin{array}{l}\text { '...at the start; I was doing the clinic with the regular pharmacist } \\
\text { being on at the same time in another room. I now feel more } \\
\text { comfortable having to do that in that setting now.' (P8) }\end{array}$ & $\mathrm{N} / \mathrm{A}$ \\
\hline
\end{tabular}




\begin{tabular}{|c|c|c|c|}
\hline Theme & Sub-Theme & Exemplar Enabler Quote & Exemplar Barrier Quote \\
\hline \multirow[t]{5}{*}{$\begin{array}{l}\text { Competing } \\
\text { priorities }\end{array}$} & \multirow[t]{3}{*}{$\begin{array}{l}\text { Additional } \\
\text { resource } \\
\text { required }\end{array}$} & \multirow{3}{*}{$\begin{array}{l}\text { Using temporary resource to demonstrate cost-effectiveness } \\
\text { leading to extra resource to expand outpatient role further: 'When } \\
\text { I first started, I was only two days a week, and then we did quite a } \\
\text { lot of work around the tapering and the cost-savings and at that } \\
\text { point I was offered a third day [external MDT funding] because } \\
\text { finance said from the savings made, they could offer me a third } \\
\text { day'. (P6) }\end{array}$} & $\begin{array}{l}\text { '...there would need to be some sort of backfill; } \\
\text { that's the basic problem because we're a small } \\
\text { team who cover a large unit; the same as } \\
\text { everywhere I'm sure.' (P13) }\end{array}$ \\
\hline & & & $\begin{array}{l}\text { 'I think sometimes we barely even fulfil our } \\
\text { inpatient commitments let alone to get out into } \\
\text { resource centres to start setting up clinics.' (P9) }\end{array}$ \\
\hline & & & $\begin{array}{l}\text { 'I think it's probably due to the challenges of } \\
\text { staffing and because of the staffing this means } \\
\text { that people worry about the inpatient service } \\
\text { before they even think about new service } \\
\text { developments.' (P11) }\end{array}$ \\
\hline & \multirow[t]{2}{*}{$\begin{array}{l}\text { Inpatient } \\
\text { workload } \\
\text { prioritised }\end{array}$} & \multirow[t]{2}{*}{$\begin{array}{l}\text { Making informal arrangements with the pharmacy team prioritise } \\
\text { outpatient role development: '...when you had your clinic day you } \\
\text { just kind of had to build in cover, from your team. So, depending } \\
\text { on where I was, someone would be able to cover where I was or } \\
\text { what I was meant to be doing that afternoon, and vice versa.' (P4) }\end{array}$} & $\begin{array}{l}\text { 'I suppose fundamentally the most critical thing } \\
\text { is ward-based duties such as: urgent clinical } \\
\text { queries and discharge prescriptions because } \\
\text { that has to happen for the maintenance of } \\
\text { basic hospital.' (P3) }\end{array}$ \\
\hline & & & $\begin{array}{l}\text { Fear of the consequences if the inpatient } \\
\text { workload is perceived to have been sacrificed: } \\
\text { 'Because if I'm pulled from a clinic to do my } \\
\text { other roles there's nobody to fill that and that } \\
\text { would impact my colleagues, it'll impact patient } \\
\text { care like for example, confirming meds and all } \\
\text { that kind of thing'. (P13) }\end{array}$ \\
\hline \multirow[t]{2}{*}{$\begin{array}{l}\text { Macro level } \\
\text { pharmacy } \\
\text { working }\end{array}$} & $\begin{array}{l}\text { Whole System } \\
\text { Working }\end{array}$ & $\begin{array}{l}\text { Whole-System working present: "there was, eh, agreement that } \\
\text { there would be some appointments across [the health authority] } \\
\text { which would have a split component of primary care and acute... } \\
\text { (P10) }\end{array}$ & $\begin{array}{l}\text { Whole-System working absent: '...I am just } \\
\text { maybe a bit bitter that the primary care } \\
\text { pharmacists are getting to do [clinics] because } \\
\text { that is something I wanted to do at one point'. } \\
\text { (P9) }\end{array}$ \\
\hline & $\begin{array}{l}\text { Need for } \\
\text { widespread } \\
\text { change }\end{array}$ & $\begin{array}{l}\text { Changed other aspects of the team to facilitate outpatient role: '... } \\
\text { we've moved a lot of the work on to the technicians' role, where } \\
\text { we can, to be able to free up pharmacist time. So, I think we're } \\
\text { more efficient now than we used to be with the pharmacist time.' } \\
\text { (P1) }\end{array}$ & $\begin{array}{l}\text { Believes Change Needs to be Beyond Their } \\
\text { Level of Scope: 'I think there needs to be a } \\
\text { significant overhaul ... in the way that we } \\
\text { operate because there is limited sustainability } \\
\text { and wiggle-room for conducting outpatient } \\
\text { clinics. ... it's bigger than just being able to } \\
\text { reshuffle individual pharmacy departments in } \\
\text { order to have pharmacists introduce } 1 \text { or } 2 \text { new } \\
\text { clinics ...' (P3) }\end{array}$ \\
\hline \multirow{3}{*}{$\begin{array}{l}\text { External } \\
\text { stakeholder } \\
\text { relationships }\end{array}$} & \multirow{2}{*}{$\begin{array}{l}\text { MDT } \\
\text { recognition of } \\
\text { pharmacist } \\
\text { outpatient } \\
\text { role }\end{array}$} & \multirow{2}{*}{$\begin{array}{l}\text { Positive MDT relationships resulting in more opportunities to } \\
\text { progress outpatient role: '...they [MDT] were trying to find a way } \\
\text { that I could help their service even more and they needed times } \\
\text { freed up for them to take on more acute clinics and patient } \\
\text { assessment clinics, and it made sense for a pharmacist to do the } \\
\text { therapeutic drug monitoring.' (P6) }\end{array}$} & $\begin{array}{l}\text { Under-developed MDT Relationships Blocking } \\
\text { Progress: }\end{array}$ \\
\hline & & & $\begin{array}{l}\text { 'I think there's a lack of a recognition or } \\
\text { appreciation for what a pharmacist's role is, } \\
\text { particularly within acute care. I think a lot of } \\
\text { people see us as some sort of 'prescription } \\
\text { provider' rather than an advisory or patient } \\
\text { management service....' (P15) }\end{array}$ \\
\hline & $\begin{array}{l}\text { Patient } \\
\text { recognition of } \\
\text { pharmacist } \\
\text { outpatient } \\
\text { role }\end{array}$ & $\begin{array}{l}\text { Positive patient feedback after experiencing a pharmacist-led } \\
\text { clinic: 'Yeah, the patients love it. They think it's great. They love } \\
\text { having someone who will talk to them about what's going to } \\
\text { happen with their medicines.' (P13) }\end{array}$ & N/A \\
\hline
\end{tabular}

\section{Clinical or service need}

Most pharmacists providing an outpatient clinic described its establishment following an increased service or clinical demand. Examples of clinical demands were: the need for the therapeutic monitoring of medicines, post-discharge medication optimisation or patients requiring consideration for a newly approved medicine.

\section{Individual psychological factors}

\section{Personal motivation}

All participants cited a personal motivation to progress their career and achieve greater job satisfaction through clinic provision. However, confidence and a locus of control frequently regulated their ability to achieve this.

Confidence 
Limited experience in the clinic environment was a major obstacle, with most participants disclosing an apprehension about the potential clinical risks associated with the increased responsibility of the outpatient role. Others revealed a perceived "fear of the unknown" (Participant 4) associated with some aspects of clinic provision. Examples included: physical patient assessment, being left alone in the clinic room with a patient, or having to unexpectedly manage a very unwell or complicated patient. However, all clinic-providing pharmacists stated that these initial anxieties faded over time as they gained more confidence and experience through the sustained delivery of their clinic.

\section{Locus of Control}

Many clinic-providing participants portrayed a strong internal locus of control where they proactively engaged with their multidisciplinary team (MDT), and drove the establishment of their outpatient roles themselves; rather than relying upon their pharmacy department or management team. This strong leadership often fostered creative solutions to barriers and facilitated external funding and resource for their outpatient role.

In contrast, an external locus of control predominated in the non-clinic providers who described a need to be directly presented with opportunities and resources from either pharmacy management or the MDT; whilst some divulged previous unsuccessful requests for funding from pharmacy services. Pertinent to this was a perceived requisite to obtain permission from pharmacy management before pursuing potential outpatient roles within their MDTs. However, there were no formal examples of permission being denied, and even departmental assurances about the non-requirement for permission did not always provide participants with reassurance.

\section{Clinic structure and processes}

\section{Defined patient cohorts}

Clinic-providing pharmacists detailed how their role was created to provide a service to a clearly defined cohort of patients, and that they had a clear understanding with their MDT about what patients they would review. Once they became more comfortable with their role, they were provided with further opportunities to take responsibility for an expanded cohort of patients. In some cases, this led to even more resource to continue and expand their outpatient role within their MDT.

\section{Integration within standard patient treatment pathways}

All clinic providers could clearly define their MDT outpatient model and how patients were referred to their pharmacist-led clinic. Participants were able to detail how their clinic improved the overall service efficiency, sometimes within a pre-defined MDT framework and evaluation plan which included a protected clinic slot within the MDT outpatient model.

\section{Exemplar peers}

The clinic providers highlighted the value of collaborating with a network of pharmacists who were already providing a clinic, similar to their own. However, non-clinic providers revealed that without an exemplar they struggled to establish a new clinic, or expand their existing role within their MDT.

\section{Practical and administrative Support}

All participants disclosed how their lack of knowledge about the processes for establishing a clinic hindered their progress in implementing them. However, clinic providers described how administrative support from within their MDT allowed them to better manage the administrative tasks and workload associated with their outpatient clinic (e.g. dictation). The biggest physical barrier to clinic provision was the need for clinic space, though the MDT provided this in most cases. The provision of support from other MDT members was viewed as essential by all clinic-providing pharmacists to assist with the progression of their clinic training and integration into the MDT outpatient model.

\section{Additional clinical skills and training}

\section{Prescribing, examination and consultation skills}

Most clinic-providing pharmacists acknowledged the benefits of obtaining and developing extra clinical skills and training (e.g. physical examination). However, despite obtaining more additional clinical skills and post-graduate qualifications (see Table 1), the non-clinic providers perceived a need for further clinic-specific skills and training. Others highlighted that until they had obtained their independent prescribing qualification, they were unable to provide the clinic, or were reliant on other MDT members to carry out prescribing activities for their patients.

\section{Mentorship and preceptorship of clinical skills}

Clinic-providing pharmacists described the value of having a mentor to support their training. Some recounted shadowing and observing their peers or MDT colleagues who were already running a similar type of clinic, and explained that this allowed them to gain a better understanding of the clinic setting and specialist practice. Others described the benefits of having a preceptor who assessed their individual progress and level of competency, in addition to providing clinical support and reassurance during the earlier stages of their training and clinic provision.

\section{Competing priorities}

\section{Additional resource required}

For most non-clinic providers, it was felt that more resource or some kind of "backfill" (Participants 3, 9, and 13) was essential to allow them the opportunity to expand their inpatient role into the outpatient setting. Many felt that the current staffing within their hospital pharmacy team was insufficient to cover 
their inpatient workload and commitments; in general, or with reference to specific tasks (e.g. medicines reconciliation, screening discharge prescriptions).

Clinic-providing pharmacists detailed how initially they either: had temporary (e.g. funding to provide a clinic 2 days per week) or no extra resource, but managed to demonstrate cost-effectiveness and service efficiency through their outpatient role which resulted in the provision of extra resource from the directorate, and allowed them to further develop their role within the outpatient service.

\section{Inpatient workload prioritised}

Most non-clinic providers revealed that the inpatient workload was their priority and that it was unclear to them if clinic provision was a priority. Many could not see beyond their inpatient commitments to afford time to explore opportunities within the outpatient setting. Some described a fear of the potential consequences of sacrificing their inpatient workload and were concerned of the potential impact this would have on their pharmacy colleagues or other HCPs based in the clinical areas they cover.

Some clinic-providing pharmacists explained that, despite having no extra resource, they managed the inpatient workload and prioritised their outpatient role through informal arrangements with the rest of their hospital pharmacy team (e.g. arranged cover for their workload during their protected clinic time). Others described having flexible working-time arrangements between their MDTs and their pharmacy department to facilitate the expansion of their role into the outpatient setting.

\section{Macro level pharmacy working Whole system working}

Many participants highlighted that they felt there were differences in the opportunities available for different pharmacists in different areas of practice; the most commonly cited example was the greater prioritisation of service development in primary care over the secondary care setting. However, this feeling of inequality was even felt between different pharmacy teams within the same hospital. Some non-clinic providers were concerned that the potential outpatient service they could provide in one hospital site would not necessarily be replicable in another. Conversely, clinic-providers described coordinated working across traditional boundaries with pharmacy colleagues from different sectors and locations; utilising shared resources to facilitate expanded outpatient services.

\section{Need for widespread change}

A desire for widespread change at the health authority level was pertinent amongst all pharmacists, and changing current practice at individual hospital sites or teams was deemed insufficient to allow the wider progression of the pharmacist role to the outpatient setting. Some participants, whether they provided a clinic or not, expanded on this and highlighted a need for prioritising personal and service development, and that this needed to be made clearer to facilitate this large-scale change.

One proposed solution from many clinic- and non-clinic providers was a greater role for their technician colleagues to take on inpatient-associated tasks that were traditionally only carried out by pharmacists (e.g. medicines reconciliation); two pharmacists explained how they have already integrated clinical technicians within their teams to allow them to prioritise the expansion of their outpatient clinic role.

\section{External stakeholder relationships}

\section{MDT recognition of pharmacist outpatient role}

MDT awareness of the potential benefits that a pharmacist could bring to their teams was viewed as essential; all participants explained that without pharmacy promotion, potential clinic-providing opportunities would likely go to other HCPs. Many non-clinic providers desired senior pharmacist support to facilitate these external relationships, and to promote the pharmacist role within the outpatient setting at the executive level. However, despite not yet approaching MDT members themselves, most revealed a belief that MDT members would support the idea of a pharmacist within their outpatient service, and that this was not a barrier. Conversely, clinic-providing pharmacists explained that after promoting their role for a period of time, their MDT is aware of their value to such an extent that they present new potential opportunities directly to them.

\section{Patient recognition of pharmacist outpatient role}

Clinic and non-clinic providers discussed the potential benefits that positive patient recognition of the pharmacist can have to enabling new opportunities for clinic provision. Some reported positive patient feedback, whilst others revealed patient-reported gaps in their current service provision by other HCPs, especially in relation to their medicines management.

A visual illustration of how all of these themes relate over time at different stages of clinic provision is shown in Fig. 1.

\section{Discussion}

\section{Statement of key findings}

Participants in this study described multiple complex overlapping enablers and barriers to clinic provision. These included: clinic prerequisites and requirements, as well as knowledge and support for the practical and clinical aspects of clinic provision; individual psychological factors and competing 
priorities; pharmacy-team specific factors, from the micro to the macro level; competing priorities; the roles of preceptors, mentors and peers; and relationships with external stakeholders, such as the MDT and patients.

Clinic-providing pharmacists frequently revealed the benefits of obtaining several clinic pre-requisites such as: a clear service need, support and resource from senior hospital department staff, a clearly defined cohort of patients to manage, MDT integration and support, administrative support, and protected clinic slots and physical spaces. Globally, these are all established enablers to clinic provision by other HCPs [25, 46, 47], with some of these also potentially aiding the progression of clinical pharmacy services and independent prescribing activities $[26,27,48,49]$.

Despite having achieved a greater number of additional clinical skills and post-graduate qualifications, the desire for further skills and training amongst non-clinic providing pharmacists was prominent; indicating that the training provided by current post-graduate courses may be inadequate to overcome certain practical barriers. With participants in our study highlighting the benefits of mentorship and preceptorship; more clinic-specific training and direct supervision which incorporates these, seems a logical approach.

Individual psychological factors predominated throughout the interviews, and are widely reported worldwide as barriers to pharmacists progressing their roles, and undertaking clinical activities such as independent prescribing and research [27, 49-53]. Our findings that MDT integration and support gradually addressed the issues of confidence and clinical competency, are also supported by the literature [48-50]. However, as well as at the individual level, participants revealed organisational level features. Non-clinic providers disclosed a perceived need for permission from senior pharmacists and pharmacy services. This is substantiated by existing literature that details a lack of progression in clinical activities carried out by pharmacists without management approval and support $[27,49,50,54]$. However, in our study there were no formal cases of participants being denied permission; this fatalism has previously been highlighted as a barrier to NHS pharmacists undertaking research [54].

The need to overcome barriers with creative solutions that result in the implementation of their outpatient role was evident in our study. This requisite for creative leadership to facilitate clinic provision is not unique to pharmacists [25]. Participants revealed competing individual priorities and perceived differences between different pharmacy teams in hospitals and other settings; these hospital-based issues appear to also be present in other countries [27].

Taken collectively, these issues raise a broader question; whose job is it to develop new services, clinicians or organisations/managers?

Although our inductive analysis was not framed a-priori around implementation science, our findings fit well into the five domains described in the Consolidated Framework For Implementation Research [55]; intervention characteristics (e.g. independent prescribing and additional clinical skills), outer setting (e.g. multidisciplinary integration and relationships), inner setting (e.g. department vision, competing priorities, protected time for clinics), individuals (e.g. confidence, locus of control), and the process of implementation (e.g. preceptorship, practical and admin elements of setting a clinic up). Utilising such frameworks may offer means to realise changes at the macro-level.

\section{Strengths \& Weaknesses}

This study not only produced qualitative data about the barriers, but also detailed enablers from the actual insights and experiences of participants that succeeded in a system where these barriers are present to now provide clinics routinely as part of their role.

This evaluation covered the largest health authority in Scotland, and our purposive sampling strategy enabled us to obtain qualitative data from clinic- and non-clinic providing hospital pharmacists, with a variety of different demographic and professional characteristics [30, 31].

There were some limitations. The choice to use an inductive approach to coding the qualitative data was mainly driven by the lack of existing knowledge on the provision of pharmacist-led clinics, and a desire to reduce any pre-conceptions about potential themes [37, 38]. The interviewer (GB) was known in a professional capacity by some participants which may have introduced some response bias. However, the potential benefits of interviewer-respondent familiarity and rapport have been reported, but the effects of this on the quality of data are still not fully understood [56-61]. This study was carried out within one regional health authority and it is unclear if all of these findings would be applicable to other health authorities.

\section{Interpretation \& Further Research}

The transformation of pharmacy services have already been highlighted nationally, and our study confirms that these will also continue to be essential for the development of the pharmacist-led outpatient clinics [62-64]. Our study suggests that individual- or hospital-level changes alone will be insufficient to progress wholesale change. However, our study also hints that many individual barriers may be secondary to discord in the current workforce model as to whose responsibility it is to take forward new service developments (i.e. where should the locus of control sit?). Scotland is beginning to address this issue through the publication of national pharmacist career pathway review, and the operationalisation of new Royal Pharmaceutical Society professional curricula [63]. Further research would need to test how to implement, and to what extent pharmacists accept, responsibilities of formal distributed leadership [65]. Broader work is also required within NHS Scotland to define and implement appropriate support-structures [66]. Prospective research should assess the impact of this vision on professional confidence and efficacy, and ultimately outpatient clinic provision.

\section{Conclusion}

The complex enablers and barriers to hospital pharmacists providing outpatient clinics are multifaceted and will unlikely be resolved by one single intervention. Changes are required at the micro- and macro-level, with distributed leadership and transformation remaining crucial. The forthcoming implementation of new professional curricula may enable pharmacists to overcome the individual and systematic barriers that prevent them from currently progressing the development of modern outpatient services; prospective research needs to accompany this vision.

Page $11 / 15$ 


\section{Declarations}

Acknowledgements: The authors would like to thank all the pharmacists who participated in this study. Funding: This research received no specific grant from any funding agency in the public, commercial, or not-for-profit sectors. Conflicts of interest: None.

\section{References}

1. Pande S, Hiller JE, Nkansah N, et al. The effect of pharmacist-provided non-dispensing services on patient outcomes, health service utilisation and costs in low- and middle-income countries. Cochrane Database Syst Rev. 2013 Feb 28; (2): CD010398. doi: 10.1002/14651858.CD010398. PMID: 23450614

2. Nkansah N, Mostovetsky O, Yu C, et al. Effect of outpatient pharmacists' non-dispensing roles on patient outcomes and prescribing patterns. Cochrane Database Syst Rev. 2010 Jul 7; (7): CD000336. doi: 10.1002/14651858.CD000336.pub2. PMID: 20614422; PMCID: PMC7087444.

3. Ryan R, Santesso N, Lowe D, et al. Interventions to improve safe and effective medicines use by consumers: an overview of systematic reviews. Cochrane Database Syst Rev. 2014 Apr 29; (4): CD007768. doi: 10.1002/14651858.CD007768.pub3. PMID: 24777444; PMCID: PMC6491214.

4. Weeks G, George J, Maclure K, et al. Non-medical prescribing versus medical prescribing for acute and chronic disease management in primary and secondary care. Cochrane Database Syst Rev. 2016 Nov 22; 11 (11): CD011227. doi: 10.1002/14651858.CD011227.pub2. PMID: 27873322; PMCID: PMC6464275.

5. Poh EW, McArthur A, Stephenson M, et al. Effects of pharmacist prescribing on patient outcomes in the hospital setting: a systematic review. JBI Database System Rev Implement Rep. 2018 Sep; 16 (9): 1823-1873. doi: 10.11124/JBISRIR-2017-003697. PMID: 30204671.

6. Ian Bates, Lina R, Bader K, Galbraith. A global survey on trends in advanced practice and specialisation in the pharmacy workforce. International Journal of Pharmacy Practice. 2020 Apr; 28 (2): 173-181. doi: 10.1111/ijpp.12611.

7. Lina R, Bader I, Bates K, Galbraith. Trends in advanced practice and specialisation in the global pharmacy workforce: a synthesis of country case studies. International Journal of Pharmacy Practice. 2020 Apr; 28 (2): 182-190. doi: 10.1111/ijpp.12612.

8. Middleton H. Why advanced practice is not the same as specialist. Clinical Pharmacist. 2012; 4. doi: 10.1211/PJ.2012.1.89322.

9. International Pharmaceutical Federation (FIP). Advanced Practice and Specialisation in Pharmacy: Global Report 2015 [internet]. The Hague: International Pharmaceutical Federation; 2015. Available from https:// (Accessed: 14 Feb 2022).

10. Department of Health. Improving Patients' Access to Medicines: A Guide to Implementing Nurse and Pharmacist Independent Prescribing within the NHS in England [internet]. London (UK). Department of Health; 2006 Apr. Available from:

https://webarchive.nationalarchives.gov.uk/20130105033522/

http://www.dh.gov.uk/prod_consum_dh/groups/dh_digitalassets/@dh/@en/documents/digitalasset/dh_4133747.pdf (Accessed: 14 Nov 2020).

11. General Pharmaceutical Council. Standards for the education and training of pharmacist independent prescribers [internet]. London (UK): General Pharmaceutical Council; 2019 Jan. Available from: https://www.pharmacyregulation.org/sites/default/files/document/standards-for-the-educationand-training-of-pharmacist-independent-prescribers-january-19.pdf (Accessed: 14 Nov 2020).

12. O'Brien N, Hoskins C. Pilot of a Pharmacist Independent Prescriber in Orthopaedic Admissions suite (OAS) to support the Enhanced Recovery After Surgery (ERAS) project for patients undergoing Hip and Knee replacement Surgery and to reduce length of stay. UKCPA Joint Poster presentation at the National Conference; 2014 April 4-6; Manchester (UK). Available from: http://ukclinicalpharmacy.org/wp-content/uploads/2017/05/UKCPAGHP_Conference_Abstracts_April2014.pdf (Accessed: 14 Nov 2020).

13. Baqir W, Crehan O, Murray R, et al. Pharmacist prescribing within a UK NHS hospital trust: nature and extent of prescribing, and prevalence of errors. Eur J Hosp Pharm. 2014;22:79-82. doi:10.1136/ejhpharm-2014-000486.

14. Rush C, Forsyth P, Moir L, et al. Collaborative care with a pharmacist improves optimisation of secondary prevention medication after discharge in patients with left ventricular systolic dysfunction due to acute myocardial infarction. Eur J Heart Fail. 2015;17(pp 341):1. doi:10.1002/ejhf.277.

15. Vaghela T, Ramesh C. Impact of change in practice: pharmacist-led respiratory syncytial virus (RSV) immunoprophylaxis clinic. Arch Dis Child. 2011;96(4):e1. doi:10.1136/adc.2011.211243.7.

16. Scottish Government. Public Health Priorities for Scotland [internet]. Edinburgh (Scotland): The Scottish Government; 2018 Jun. Available from: https://www.gov.scot/publications/scotlands-public-health-priorities/ (Accessed: 14 Nov 2020).

17. Scottish Government. The Scottish Health Survey 2019 - volume 1: main report [internet]. Edinburgh (Scotland): The Scottish Government; 2020 Sep. Available from: https://www.gov.scot/publications/scottish-health-survey-2019-volume-1-main-report/ (Accessed: 14 Nov 2020).

18. Information Services Division: Public Health Scotland. Acute hospital activity and NHS Beds Information for Scotland (Annual - Year ending 31 March 2019) [internet]. Edinburgh (Scotland): Public Health Scotland; 2019 Sep. Available from https://beta.isdscotland.org/find-publications-anddata/health-services/hospital-care/acute-hospital-activity-and-nhs-beds-information-annual/10-september-2019/ (Accessed: 29 Nov 2020).

19. Scottish Government. A National Clinical Strategy For Scotland [internet]. Edinburgh (Scotland): The Scottish Government; 2016 Feb. Available from: https://www.gov.scot/publications/national-clinical-strategy-scotland/ (Accessed: 14 Nov 2020).

20. Royal College of Physicians. Outpatients: The future - adding value through sustainability [internet]. London (UK): Royal College of Physicians; 2018. Available from: https://www.rcplondon.ac.uk/projects/outputs/outpatients-future-adding-value-through-sustainability (Accessed: 14 Nov 2020).

21. Scottish Government. The Modern Outpatient: A Collaborative Approach 2017-2020 [internet]. Edinburgh (Scotland): The Scottish Government; 2016 Dec. Available from: https://www.gov.scot/publications/modern-outpatient-collaborative-approach-2017-2020/ (Accessed: 14 Nov 2020). 
22. Scottish Government. Achieving Excellence in Pharmaceutical Care: A Strategy for Scotland [internet]. Edinburgh (Scotland): The Scottish Government; 2017 Aug. Available from: http://www.gov.scot/Publications/2017/08/4589 (Accessed: 14 Nov 2020).

23. Scottish Government. Plan For A Scotland: 2016-17 [internet]. Edinburgh (Scotland): The Scottish Government; 2016 Sep. Available from: https://www2.gov.scot/Resource/0050/00505210.pdf (Accessed: 14 Nov 2020).

24. Forsyth P, Moir L, Speirits I, et al. Improving medication optimisation in left ventricular systolic dysfunction after acute myocardial infarction. BMJ Open Qual. 2019;8(3):e000676. doi:10.1136/bmjoq-2019-000676. PMID: 31544164; PMCID: PMC6730630.

25. Haines KJ, McPeake J, Hibbert E, et al. Enablers and Barriers to Implementing ICU Follow-Up Clinics and Peer Support Groups Following Critical IIIness: The Thrive Collaboratives. Crit Care Med. 2019 Sep;47(9):1194-200. doi: 10.1097/CCM.0000000000003818. PMID: 31241499; PMCID: PMC6699486.

26. Salgado TM, Moles R, Benrimoj SI, et al. Exploring the role of renal pharmacists in outpatient dialysis centres: a qualitative study. Int J Clin Pharm. 2012 Aug; 34 (4): 569-578. doi: 10.1007/s11096-012-9645-z.

27. Brazinha I, Fernandez-Llimos F. Barriers to the implementation of advanced clinical pharmacy services at Portuguese hospitals. Int J Clin Pharm. 2014 Oct;36(5):1031-8. doi:10.1007/s11096-014-9991-0.

28. NHS Greater Glasgow and Clyde [internet]. About us: who we are and what we do. Available from: https://www.nhsggc.org.uk/about-us/who-we-arewhat-we-do/ (Accessed: 29 Nov 2020).

29. Scottish Government. Scottish Index of Multiple Deprivation 2020: introduction [internet]. Edinburgh (Scotland): Scottish Government; 2020 Jan. Available from: https://www.gov.scot/publications/scottish-index-multiple-deprivation-2020/ (Accessed: 08 Dec 2020).

30. Etikan I, Musa SA, Alkassim RS. Comparison of convenience sampling and purposive sampling. Am J Theor Appl Stat. 2016;5:1-4. doi:10.11648/j.ajtas.20160501.11.

31. Ritchie J, Lewis J, Elam G, Tennant R, Rahim N. Chapter 5: Designing and Selecting Samples. In: Ritchie J, Lewis J, McNaughton Nicolls C, Ormston R, editors. Qualitative Research Practice: A Guide for Social Science Students and Researchers, 2nd edition. London (UK): SAGE Publications; 2013. p 111-119.

32. Adler PA, Adler P. Limitations to sample pools. In: Baker SE, Edwards R, Doidge M, editors. National centre of research review paper: how many qualitative interviews is enough?: expert voice and early career reflections on sampling and cases in qualitative research. Southampton (UK): National Centre for Research Methods; 2012. p. 10.

33. Guest G, Bunce A, Johnson L. How Many Interviews Are Enough?: An Experiment with Data Saturation and Variability. Field Methods. 2006;18(1):5982. doi:10.1177/1525822X05279903.

34. Namey E, Guest G, McKenna K, et al. Evaluating Bang for the Buck: A Cost-Effectiveness Comparison Between Individual Interviews and Focus Groups Based on Thematic Saturation Levels. Am J Evaluation. 2016;37(3):425-40. doi:10.1177/1098214016630406.

35. Microsoft [Internet]. Microsoft 365: Microsoft Teams. Available from: https://www.microsoft.com/en-gb/microsoft-365/microsoft-teams/group-chatsoftware (Accessed: 08 Dec 2020).

36. QSR International [Internet]. NVivo: Qualitative Data Analysis. Available from: https://www.qsrinternational.com/nvivo-qualitative-data-analysissoftware/about/nvivo (Accessed: 08 Dec 2020).

37. Braun V, Clarke V. Using thematic analysis in psychology. Qual Res Psychol. 2006;3:77-101. doi:10.1191/1478088706qp063oa.

38. Nowell LS, Norris JM, White DE, et al. J. Thematic Analysis: Striving to Meet the Trustworthiness Criteria. Int J Qualitative Methods. 2017;16:1-13. doi:10.1177/1609406917733847.

39. DeSantis L, Ugarriza DN. The concept of theme as used in qualitative nursing research. West J Nurs Res. 2000 Apr; 22 (3): $351-372$. doi: 10.1177/019394590002200308. PMID: 10804897.

40. Webster S, Lewis J, Brown A. Chapter 4: Ethical Considerations in Qualitative Research. In: Ritchie J, Lewis J, McNaughton Nicolls C, Ormston R, editors. Qualitative Research Practice: A Guide for Social Science Students and Researchers, 2nd edition. London (UK): SAGE Publications; $2013 . \mathrm{p} 77-110$.

41. Côté L, Turgeon J. Appraising qualitative research articles in medicine and medical education. Med Teach. 2005; 27 (1): 71-75. doi: 10.1080/01421590400016308. PMID: 16147774.

42. Joffe H. Chapter 15: Thematic Analysis. In: Harper D, Thompson A, editors. Qualitative Research Methods in Mental Health and Psychotherapy: A Guide for Students and Practitioners. Chichester (UK): Wiley-Blackwell; 2012. pp. 209-24.

43. Tong A, Sainsbury P, Craig J. Consolidated criteria for reporting qualitative research (COREQ): a 32-item checklist for interviews and focus groups. Int J Qual Health Care. 2007;19(6):349-57. doi:10.1093/intqhc/mzm042.

44. Scottish Terms and Conditions Committee (STAC). Proposal for Reform of Agenda for Change in NHS Scotland (Framework Agreement) [internet]. 2018 Aug. Available from: https://www.stac.scot.nhs.uk/wp-content/uploads/Test.pdf (Accessed on 6 Dec 2020).

45. General Medical Council [internet]. GMC approved postgraduate curricula. Available from: https://www.gmc-uk.org/education/standards-guidance-andcurricula/curricula (Accessed: 29 Nov 2020).

46. Hatchett R. Nurse-led clinics: 10 essential steps to setting up a service. Nurs Times. 2008;104(4):62-4.

47. Berei T, Forsyth P, Balakumaran K, et al. Implementing Nonphysician Provider Guideline-Directed Medical Therapy Heart Failure Clinics: A Multi-National Imperative. J Card Fail. 2021; 27 (8): 896-906. doi: 10.1016/j.cardfail.2021.06.001. PMID: 34364666.

48. Fisher J, Kinnear M, Reid F, et al. What supports hospital pharmacist prescribing in Scotland? - A mixed methods, exploratory sequential study. Res Social Administrative Pharm. 2018;14:488-97. doi:10.1016/j.sapharm.2017.06.007. 
49. Graham-Clarke E, Rushton A, Noblet T, et al. Facilitators and barriers to non-medical prescribing - A systematic review and thematic synthesis. PLoS One. 2018 Apr; 13 (4): e0196471. doi: 10.1371/journal.pone.0196471. PMID: 29709006; PMCID: PMC5927440.

50. General Pharmaceutical Council. Prescribers Survey Report [internet]. London (UK): General Pharmaceutical Council; 2016 May. Available from: https://www.pharmacyregulation.org/sites/default/files/document/gphc_prescribers_survey_report-may-2016.pdf (Accessed: 14 Nov 2020).

51. Frankel GE, Austin Z. Responsibility and confidence: Identifying barriers to advanced pharmacy practice. Can Pharm J (Ott). 2013 May;146(3):155-61. doi:10.1177/1715163513487309.

52. Rosenthal M, Austin Z, Tsuyuki RT. Barriers to pharmacy practice change: Is it our nature or nurture? Can Pharm J (Ott). 2016 Nov;149(6):317-9. doi:10.1177/1715163516672832.

53. Rosenthal M, Austin Z, Tsuyuki RT. Are Pharmacists the Ultimate Barrier to Pharmacy Practice Change? Canadian Pharmacists Journal / Revue des Pharmaciens du Canada. 2010; 143 (1): 37-42. doi:10.3821/1913-701X-143.1.37.

54. Lowrie R, Morrison G, Lees R, et al. Research is 'a step into the unknown': an exploration of pharmacists' perceptions of factors impacting on research participation in the NHS. BMJ Open. 2015 Dec 30; 5 (12): e009180. doi: 10.1136/bmjopen-2015-009180.

55. Damschroder LJ, Aron DC, Keith RE, et al. Fostering implementation of health services research findings into practice: a consolidated framework for advancing implementation science. Implement Sci. 2009; 4 (50). doi:10.1186/1748-5908-4-50.

56. Mitchell K, Wellings K, Elam G, et al. How can we facilitate reliable reporting in surveys of sexual behaviour? Evidence from qualitative research. Cult Health Sexuality. 2007;9(5):519-31. doi:10.1080/13691050701432561.

57. Tu SH, Liao PS. Social Distance, Respondent Cooperation and Item Nonresponse in Sex Survey. Qual Quantity. 2007;41:177-99. doi:10.1007/s11135007-9088-0.

58. Rodriguez LA, Sana M, Sisk B. Self-administered Questions and Interviewer-Respondent Familiarity. Field Methods. 2015;27(2):163-81. doi:10.1177/1525822X14549315.

59. Rossier C. Estimating induced abortion rates: A review. Stud Fam Plann. 2003;34(2):87-102. doi: 10.1111/j.1728-4465.2003.00087.x.

60. Weinreb AA, Sana M, Stecklov G. A test of the stranger-interviewer norm in the Dominican Republic. Popul Stud (Camb). 2016;70(1):73-92. doi:10.1080/00324728.2016.1139740.

61. Stecklov G, Weinreb AA, Sana M. Family Planning for Strangers: An Experiment on the Validity of Reported Contraceptive Use. PLoS One. 2015; 10 (8): e0136972. doi: 10.1371/journal.pone.0136972. PMID: 26322898; PMCID: PMC4554992.

62. NHS Education for Scotland. Pharmacist Career Framework Review - Report of the Review Advisory Group [internet]. Edinburgh (Scotland): NHS Education for Scotland; 2020 Sep. Available from: https://www.nes.scot.nhs.uk/media/vzahxc4w/final-pharmacy-pg-framework-review_v1-1.pdf (Accessed 14 Jan 2021).

63. Royal Pharmaceutical Society. The RPS Advanced Pharmacy Framework (APF) [internet]. London (UK): Royal Pharmaceutical Society; 2013. Available from:

https://www.rpharms.com/Portals/0/RPS\%20document\%20library/Open\%20access/Frameworks/RPS\%20Advanced\%20Pharmacy\%20Framework.pdf (Accessed 14 Jan 2021)

64. Royal Pharmaceutical Society. Professional Standards for Hospital Pharmacy Services - Version 3 [internet]. London (UK): Royal Pharmaceutical Society; 2017 Dec. Available from: https://www.rpharms.com/recognition/setting-professional-standards/professional-standards-for-hospitalpharmacy (Accessed 14 Jan 2021).

65. Martin G, Beech N, Maclntosh R, et al. Potential challenges facing distributed leadership in health care: evidence from the UK National Health Service. Sociol Health IIIn. 2015 Jan;37(1):14-29. doi:10.1111/1467-9566.12171. Epub 2014 Dec 20. PMID: 25529349.

66. Forsyth P, Rushworth GF. Advanced pharmacist practice: where is the United Kingdom in pursuit of this 'Brave New World'?. Int J Clin Pharm. 2021 May 15. https://doi.org/10.1007/s11096-021-01276-5. Epub ahead of print. PMID: 33991288.

\section{Figures}


Clinical need / Service need

Personal motivation / Internal locus of control

Multidisciplinary integration \& relationships

\begin{tabular}{|l|l|l} 
Exemplar peer / IP \& additional skills & Preceptorship & Peer review network
\end{tabular}

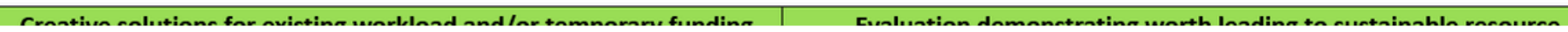

Figure 1

See image above for figure legend

\section{Supplementary Files}

This is a list of supplementary files associated with this preprint. Click to download.

- SupplementaryFile1 InterviewSchedule1.docx

- SupplementaryFile2InterviewSchedule2.docx 